\title{
Interpretation of English multiple wh-questions by Japanese speakers: a missing uninterpretable feature account
}

\author{
Roger Hawkins University of Essex and \\ Hajime Hattori Aichi Prefectural University
}

Received July 2005; revised February 2006; accepted March 2006

In recent work by Tsimpli (2003) and Tsimpli and Dimitrakopoulou (to appear) an explicit claim is made about the nature of end-state grammars in older second language (L2) learners: uninterpretable syntactic features that have not been selected during first language (L1) acquisition will not be available for L2 grammar construction. Interpretable syntactic features, on the other hand, remain available (as well as the computational procedures and principles of the language faculty), even those not selected by the L1. The present study investigates this hypothesis in relation to the acquisition of the uninterpretable feature that forces $w h$-movement in interrogatives in English. Nineteen L1 speakers of Japanese (a $w h$-in-situ language that lacks the movement-forcing feature) who are highly proficient speakers of English were asked to interpret bi-clausal multiple wh-questions in English (like Where did the professor say the students studied when?). Their responses were compared with those of a native speaker control group. It is argued that the results are consistent with the unavailability of the uninterpretable feature. Two conclusions are drawn: first, that there is a critical period for the selection of uninterpretable syntactic features for the construction of mental grammars; second, that despite the observation of target-like performance by L1 Japanese speakers on English wh-interrogatives reported in a number of existing studies, caution is required in interpreting target-like performance as evidence that L2 speakers have the same underlying grammatical representations as native speakers.

Address for correspondence: Roger Hawkins, Department of Language and Linguistics, University of Essex, Wivenhoe Park, Colchester, Essex CO4 3SQ, UK; e-mail: roghawk@essex.ac.uk 


\section{Introduction}

The role of interpretable and uninterpretable syntactic features in grammatical representation has been the focus of considerable investigation in recent generative theories of second language acquisition (SLA). Interpretable syntactic features are those which, while relevant to syntactic computation, are also used by the semantic component in determining the meaning of syntactic expressions: features like [singular], [3rd person], [past] and [Q(uestion)]. Uninterpretable features are the counterparts of interpretable features (Pesetsky and Torrego, 2001) but are not usable by the semantic component. They may, however, have effects on the morpho-phonological realization of syntactic expressions. For example, a recent claim (Chomsky, 1998) is that finite $\mathrm{T}$ in English has uninterpretable person and number features. One consequence of this is that verb forms vary. For example, be in the present tense can take the forms (I) am, (she) is, (we) are. The contrast between these forms plays no role in semantic interpretation; am, is, are do not each mean something different. The person and number features that underlie $I$, she and we are, however, interpretable and the contrast between them is semantically relevant.

In recent work, Tsimpli (2003) and Tsimpli and Dimitrakopoulou (to appear) have hypothesized that uninterpretable, but not interpretable, syntactic features are problematic for second language speakers in the following way: if they are not selected from the inventory of features assumed to be given by genetic endowment (universal grammar, or UG) in the construction of a mental grammar during a 'critical period' when all such features are available, they disappear. In subsequent language acquisition, all other aspects of UG remain available: the computational devices, their associated operating principles, interpretable syntactic features and uninterpretable features already selected during the acquisition of primary grammar(s) during the critical period. ${ }^{1}$ Following Tsimpli \& Dimitrakopoulou, we refer to this as the 'Interpretability Hypothesis'.

\footnotetext{
${ }^{1}$ Work by Brown (2000) and Larson-Hall(2004) suggests that a similar phenomenon may be involved in the acquisition of phonemic contrasts. Both argue that where a speaker's primary grammar (or grammars) has not selected a contrastive feature that is required for a later-acquired L2, that contrast will not be perceived. This would be the effect of a critical period for the selection of phonemically contrastive features.
} 
The Interpretability Hypothesis makes an explicit claim about one area where L2 speaker knowledge will permanently diverge from that of native speakers. It meets Long's definition of what might constitute an interesting account of 'fossilization' in relation to ultimate attainment in SLA:

The original ... use of the term ['fossilization'] involves a potentially interesting claim that the current level of development is the permanent end-state because a learner cannot progress any further ... a claim about a loss of capacity to acquire. (Long, 2003: 518-19; emphasis in original)

Tsimpli and Dimitrakopoulou's hypothesis is an explicit claim about one locus of the loss of capacity to acquire.

It might be asked why specifically uninterpretable syntactic features should be subject to a critical period, and not features in general, or the computations, or their associated principles. Uninterpretable features are members of the set of properties that are selected in response to experience (linguistic input). Others are the interpretable syntactic and semantic features required for the assembly of lexical items, and the phonetic/phonological features that combine to produce pronounceable exponents of those items. Properties for which, by hypothesis, experience of linguistic input is not required are the semantic computations, the syntactic computations and the principles under which both operate (Chomsky, 1998). These are given by genetic endowment and are present throughout life. Critical periods are those during which experience is required to fix options offered by genetic endowment. So, in the domain of syntax, the question comes down to why uninterpretable features and not interpretable features might be subject to a critical period.

One speculative possibility is functional usefulness. There are advantages to having interpretable features available throughout life. They are required for constructing new open class lexical items. Individuals, it seems, can and do learn new items at all ages, and languages are constantly adding to their stock of open class items. The availability of interpretable features is essential to this task. Uninterpretable features, by contrast, are specified on a small number of closed class items belonging to functional categories. Their purpose is to establish stable dependencies between items in syntactic derivations. There may be functional disadvantages to having all the uninterpretable features of the UG inventory permanently available. As Eubank and Gregg 
(1999: 93) put it: ' . . if there is a pro-drop parameter, for instance, it would not do for English native speakers to be continually thrown into doubt over its value every time they heard an imperative sentence.' All the options for uninterpretable features need to be available to the child initially because the child cannot know in advance whether the linguistic input to be encountered will show evidence of pro-drop or not, involve $w h$-movement or not, will have gender concord between Ns and Ds and As, or not, and so on. But it may be functionally economical if, after a given period during which the required features are selected, unselected uninterpretable features cease to be available.

A parallel neuro-anatomical argument has to do with the conservation of energy for brain activity:

in terms of the energy that it requires, brain tissue is expensive to run. If our ancestors received little or no benefit from retaining the full capacity to learn language into adulthood, individuals would be at a disadvantage if they retained the neural scaffolding required to build the one and only language they would ever need. They would have to provide energy for a part of the brain that no longer had a useful function. (Bateson and Martin, 1999: 149)

If it is true that the brain operates under some energy efficiency constraint that 'disconnects' components not directly required for cognitive functioning after a certain time lapse, unselected uninterpretable syntactic features could be a plausible target for such disconnection. Again, this is highly speculative.

If Tsimpli \& Dimitrakopoulou's Interpretability Hypothesis is correct, i.e. that unselected uninterpretable syntactic features are subject to a critical period (as unselected features distinguishing phonemic contrasts might also be; see footnote 1), but all else determined by UG continues to constrain the development of grammars beyond the critical period, it would be expected that older L2 learners with sufficient experience of the target language will converge on grammars that are highly similar to those of native speakers of the same target language. Where, however, the target language has selected an uninterpretable syntactic feature that is not available to the L2 speaker through primary language acquisition, other options provided by UG will need to be accessed to represent the phenomenon in question in the grammar. In such cases, evidence to support the claim that there is a 'loss of capacity to acquire' will necessarily be delicate. L2 learners may appear to have acquired the relevant property on a number of performance 
measures, when in fact they have not, and are using alternative representational options made available by UG to approximate to the native grammar.

In this study we consider a case where, on a number of linguistic measures, native speakers of Japanese, which is a language that has $w h$-in-situ interrogatives and therefore lacks an uninterpretable syntactic feature in the domain of the interrogative complementizer to force movement of a wh-phrase, appear to have converged on the same representation for English interrogative wh-movement as native speakers. It will be shown, however, that on a different measure - locality constraints in multiple wh-questions such as the contrast between Who did John say bought what? and *What did John say who bought? - the Japanese speakers are not significantly different in their judgements of grammatical and ungrammatical cases. Furthermore, while they are not different from the natives in judging grammatical cases, they are significantly different in judging the ungrammatical cases. From these results, two things are argued. First, that this is support for Tsimpli's Interpretability Hypothesis. Japanese speakers have not acquired an uninterpretable feature that is present in native grammars of English, but has not been selected by Japanese, and has disappeared from the UG inventory following a critical period that ended at some point before these speakers encountered the relevant English input. By hypothesis, there is a permanent 'loss of capacity to acquire' in this domain. Second, that sometimes caution is required in treating apparent cases of target-like performance by L2 speakers as evidence for underlying target-like grammatical representations. While researchers have been justifiably careful to argue that non-target-like performance may under-represent abstract grammatical knowledge (see, for example, Lardiere, 1998a; 1998b; 2000; Prévost \& White, 2000; White, 2003a; Goad, et al., 2003), there has been a tendency to assume that performance cannot 'over-represent' knowledge, i.e. that target-like performance means target-like underlying representations. Myles (2004) has provided grounds to question this assumption in the performance of early-stage L2 speakers. A similar case is made here with respect to high proficiency L2 speakers.

The article is organized as follows. Section II describes the properties of $w h$-interrogatives, and specifically multiple $w h$-interrogatives in 
English and Japanese, and outlines the assumptions that will be made about their syntactic structure. In Section III evidence is presented from existing studies that suggests that L1 speakers of Japanese who learn English beyond childhood perform in a highly target-like manner on a number of properties of moved $w h$-interrogatives. This might lead one to claim that they have fully converged on the grammar of native speakers of English. Section IV, however, presents evidence from a study of the interpretation of English multiple $w h$-interrogatives that shows that a group of highly proficient Japanese speakers are not sensitive to superiority or subjacency effects in the same way as natives. Section V considers what other options provided by UG they might be using to represent English $w h$-interrogatives, and considers the broader implications of the results for the potential attainment of syntactic knowledge by older L2 speakers.

\section{Properties of $w h$-interrogatives in English and Japanese}

\section{Single wh-questions}

In English simple, non-echo interrogative clauses, ${ }^{2}$ a $w h$-word or phrase must be fronted, as illustrated in (1). (In the examples that follow, the position from which a constituent has moved is indicated by angled brackets $<>$ ):

1) a. What did Mary buy $<$ what $>$ yesterday?

b. * Did Mary buy what yesterday?

In Japanese, the $w h$-word/phrase remains in its first-merged position, in the unmarked case (wh-in-situ):

2) Mary-wa kinou nani-o kaimashi-ta ka? Mary-topic yesterday what-Acc buy-past Q?

'What did Mary buy yesterday?'

In English complex sentences, where the matrix clause is an interrogative and the $w h$-word/phrase is located in an embedded clause, the $w h$-word/phrase moves to the front of the matrix clause, and does so

${ }^{2}$ Echo questions are case like:

A: Uncle Tim has bought a 500cc motorbike.

$B$ : He's bought what?

They have different properties from ordinary information-seeking $w h$-interrogatives, and are not discussed here. 
cyclically, moving through the complementizer phrase of the embedded clause $^{3}$ :

3) a. What did John remember $\left[_{\mathrm{CP}}<\right.$ what $>$ Mary bought $<$ what $>$ yesterday $]$ ?

b. * Did John remember $\left[_{\mathrm{CP}}\right.$ Mary bought what yesterday]?

Again, in equivalent constructions in Japanese the wh-word/phrase remains in situ in the unmarked case:

4) a. John-wa $\left[_{C P}\right.$ Mary-ga kinou nani-o kat-ta to] oboete imasu ka? John-topic [Mary-Nom yesterday what-Acc buy-past C] remember is Q? 'What did John remember Mary bought yesterday?'

The English and Japanese interrogatives in (1)-(4) are identical in the way that what/nani are interpreted, a fact captured if the semantic component of UG is uniform across human language, and the same interpretive procedure is involved (Chomsky, 2001: 2). At the same time, the obligatory nature of $w h$-fronting in English, but its absence in Japanese, needs to be explained. The account of this assumed here follows Adger (2003: Chapter 9), whose proposals are in the spirit of the Minimalist Program. ${ }^{4}$

According to Adger, interrogatives involve an agreement dependency between an interrogative complementizer with an interpretable question feature [Q] that 'types' the clause as a question, and a constituent in the clause with an interpretable [wh] feature, marking it as a quantifier. In English, heads with a [wh] feature range over the set of humans ('who'), non-humans ('what'), locations ('where'), times ('when'), reasons ('why') and degree ('how'):

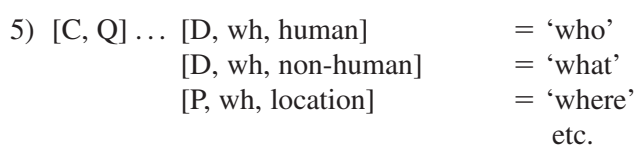

The agreement dependency is established through an uninterpretable [uwh:] feature, which is specified on $\mathrm{C}$ : [C, Q, $u$ wh:]. This invokes the operation Agree, whose function is to value and delete the

\footnotetext{
${ }^{3}$ For expository purposes, other positions the $w h$-word/phrase might have to move through are ignored.

${ }^{4}$ Adger's account differs in its technical detail from the account of $w h$-movement proposed by Chomsky (1998), and there are other conceivable alternatives; see, for example, Pesetsky, 2000. As always in acquisition research, a decision has to be made about which assumptions to make about linguistic structure. In this research we pursue the consequences of adopting Adger's proposals.
} 
uninterpretable feature. Agree takes the following form in Adger's system (2003: 169):

6) Agree: In a configuration:

$\mathrm{X}[\mathrm{F}$ : value $] \ldots \mathrm{Y}[u \mathrm{~F}:]$ or $\mathrm{X}[u \mathrm{~F}:] \ldots \mathrm{Y}[\mathrm{F}$ : value $]$

where $\ldots$ represents $\mathrm{c}$-command and $\mathrm{F}=$ a feature

F values $u \mathrm{~F}$

In the case of a $w h$-question, there are two ways in which Agree can operate. In $w h$-in-situ languages, valuing occurs directly between $[\mathrm{C}, \mathrm{Q}]$ and the target $w h$-word/phrase, without movement, as illustrated in (7):

7) $[\mathrm{C}, \mathrm{Q}, u \mathrm{wh}:] \ldots[\mathrm{D}, \mathrm{wh}] \rightarrow[\mathrm{C}, \mathrm{Q}, \mathrm{wh}] \ldots[\mathrm{D}, \mathrm{wh}]$

In Japanese, valued $[\mathrm{C}, \mathrm{Q}$, wh] has the phonological exponent $k a$, and wh-words have the exponents dare 'who', nani 'what', dokode 'where', itsu 'when', naze 'why' and dou 'how'.

In languages where $w h$-words/phrases are fronted, as in English, there is an additional requirement that valuing of [uwh:] occur within the immediate projection of interrogative C. Adger represents this requirement as an asterisked [ $\left.u \mathrm{wh}^{*}:\right]$ feature. This forces a $w h$-word/ phrase to move to the specifier of [C, Q, $u \mathrm{wh}^{*}$ :] to value [uwh*:]:

8) $\left[\mathrm{C}, \mathrm{Q}, u \mathrm{wh}^{*}:\right] \ldots[\mathrm{D}, \mathrm{wh}] \rightarrow[\mathrm{D}, \mathrm{wh}[\mathrm{C}, \mathrm{Q}, \mathrm{wh}]] \ldots<[\mathrm{D}, \mathrm{wh}]>$

Hence, while both Japanese and English interrogative complementizers have the uninterpretable feature [ $u \mathrm{wh}:]$ that ensures that a $w h$-word/ phrase is selected in the complementizer's c-command domain, English has a further uninterpretable feature that forces $w h$-word/phrase movement. An alternative way of viewing this is to take the requirement for local valuing of [uwh:] as involving a separate feature. For Chomsky (1998) this is an uninterpretable EPP (extended projection principle) feature. It is assumed here that Chomsky's EPP feature and Adger's asterisk are notational equivalents of the same idea: English has an uninterpretable feature that Japanese does not have, which drives movement of a $w h$-word/phrase to the specifier of CP.

\section{Multiple wh-questions}

One consequence of the feature-driven nature of $w h$-movement in English interrogatives is that it is subject to locality constraints imposed 
by UG. These show up when two wh-words are present in the same sentence: multiple wh-questions (MWQs). Consider, first, three grammatical MWQs. (9a-b) are single-clause interrogatives, (9c) is bi-clausal:

9) a. Who bought what?

b. Where did the students study when?

c. Where did the professor say the students studied when?

Example (9c) has two distinct readings. On one reading, where has moved from a first-merged position in the embedded clause to the front of the matrix clause. On this reading (9c) is a question about where the students studied and when they did so. On another reading, where is first-merged in the matrix clause, and (9c) is interpreted as involving two separate questions, one about when the students studied, the other about where the professor was when he gave this information. In contrast to $(9 \mathrm{a})$ and $(9 \mathrm{c})$, the questions in (10) are degraded in grammaticality (where in (10b) where is interpreted as originating in the embedded clause):

10) a. * ? What did who buy?

b. * ? Where did the professor say when the students studied?

The ungrammaticality results from a principle of syntactic computation, which requires that when a constituent moves to adjoin to a category with an uninterpretable feature, the closest constituent of the relevant type moves. There have been various formulations of this principle: e.g. Attract Closest or the Minimal Link Condition (Chomsky, 1995) and the Minimal Match Condition (Aoun \& Li, 2003). For the purposes of exposition, Radford's (2004: 200) definition of the 'Attract Closest Principle' is assumed here:

11) Attract Closest Principle: A head which attracts a given kind of constituent attracts the closest constituent of the relevant kind

In (10a), because who is the subject of the clause, it is closer to [C, Q, uwh:] than what (the object); hence, movement of what produces ungrammaticality. This is a violation known traditionally as a 'superiority violation'. In (10b), movement of where from the embedded clause to the specifier of $\left[\mathrm{C}, \mathrm{Q}, u \mathrm{wh}^{*}:\right]$ of the matrix clause also violates the Attract Closest Principle because the $\mathrm{C}$ of the lower clause 
contains the closer wh-word when: a case known traditionally as a 'subjacency violation' involving a $w h$-island. ${ }^{5}$

Observe that both sentences in (10) are ungrammatical because interrogative $\mathrm{C}$ has an uninterpretable feature that attracts a $w h$-word, and involves principle (11). Interestingly, superficially similar constructions can be derived in Japanese where a wh-word has moved, but without violation of the Attract Closest Principle. It will be suggested that this is because such movement is not forced by a [uwh:] feature. This fact will play an important part in our subsequent explanation of the performance of highly proficient Japanese speakers of L2 English. Consider examples (12) and (13):

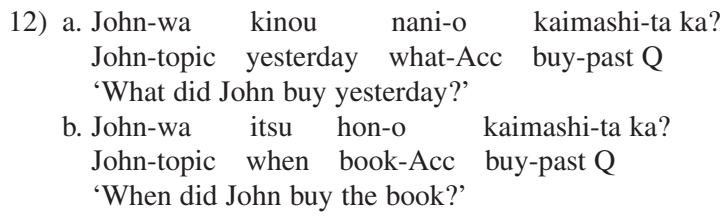

13) a. Nani-o John-wa kinou $<$ nani-o $>$ kaimashi-ta ka?

b. Itsu John-wa $<$ itsu $>$ hon-o kaimashi-ta ka?

Both (12) and (13) are grammatical. Example (12) is the unmarked word order; in (13), nani 'what' and itsu 'when' have moved in an operation known as scrambling. Most researchers agree that this operation is not driven by a [ $\left.u \mathrm{wh}^{*}:\right]$ feature of $\mathrm{C}$, but there is little consensus about what does force it (see Saito, 1992; Kobayashi, 2000; Miyagawa, 2003; Kawamura, 2004, among others, and further discussion in Section V). ${ }^{6}$

5In Chomsky's recent work (e.g. 1998; 2001) a question arises about how an interrogative [C, Q,
$u$ wh*:] in a main clause can 'see' a constituent with a [wh] feature inside an embedded clause, where
that clause constitutes a 'phase' of the derivation whose computations are complete. Consideration
of this question is beyond the scope of the present article.
${ }^{6}$ A reviewer suggests that the theoretical assumptions made here about movement of wh-words in
Japanese 'differ from possibly more "mainstream" (and nuanced) views in the literature'. However, our
assumption that Japanese scrambling of $w h$-words is not $w h$-movement of the kind found in English is
consistent with the claims of Saito and Fukui (1998) who maintain that scrambling is optional and not
motivated by feature-checking, Tanaka (1999) who argues that scrambled phrases cannot be in the
specifier of CP, and Miyagawa (2003) who, unlike Saito and Fukui, argues that scrambling is not
optional, but proposes that it is obligatory movement of either subject or object to the specifier of TP.
Crucially, Miyagawa distinguishes A-scrambling from A'-scrambling, and in the latter case proposes
that it is driven by Focus (not by a wh-feature), an idea we pursue in Section V. These, among others,
appear to be 'mainstream' proposals concerning the scrambling of wh-words/phrases in Japanese. One
study that proposes that long-distance scrambling in Japanese (but not short scrambling) is movement
to a [+WH] complementizer is Takahashi (1993). However, this does not seem to be the prevailing
view of Japanese linguists and, as argued in Section II, is based on examples whose ungrammaticality
may be the effect of constraints other than those relating to the locality requirement of $w h$-movement. 
One piece of evidence that [uwh:] is not involved is that when two $w h$-words are present, one may freely scramble over the other, as illustrated in (14):

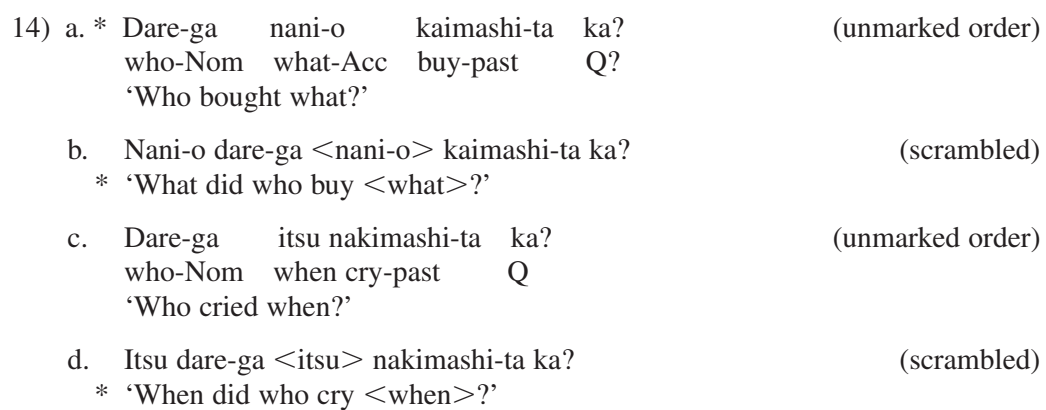

Similarly, there is no apparent violation when a wh-word scrambles across another into a higher clause:
15) a. Nani-o John-ga [dare-ga $<$ nani-o $>$ tabe-ta to $]$ it-ta no? what-Acc John-Nom [who-Nom <what-Acc $>$ eat-past that] say-past Q
* 'What did John say [who ate $<$ what $>$ ]?'

Example (15a) is taken from Takahashi (1993: 667, footnote 9) who states that 'this example does not display the superiority effect'. A Second Language Research reviewer reports that 10 Japanese speakers consulted for the review found sentence (15) unacceptable, implying that it does display a superiority effect and hence may involve [uwh:] feature-driven movement. The same reviewer also observes that Takahashi proposes several other examples that appear to violate superiority. However, Takahashi's claimed examples of superiority violations either involve $w h$-words that originate in different clauses, as in $(15 \mathrm{~b}-\mathrm{c})$, or involve the $w h$-adjunct naze 'why', as in (15d):

$\begin{array}{llllll}\text { 15) b. John-ga dare-ni } \quad[\text { Mary-ga nani-o tabeta to }] & \text { itta no? } \\ \text { John-Nom who-Dat } & \text { [Mary-Nom what-Acc } & \text { ate } & \text { that }] & \text { said } & \text { Q? } \\ \text { 'Who did John tell that Mary ate what?' } & & & & \end{array}$

c. ?? Nani-o John-ga dare-ni [Mary-ga $<$ nani-o $>$ tabeta to] itta no? What-Acc John-Nom who-Dat [Mary-Nom <what-Acc $>$ ate that] said Q?

d. * Nani-o John-wa [Mary-ga naze [Jennifer-ga $<$ nani-o $>$ tabeta to] What-Acc John-Top [Mary-Nom why [Jennifer-Nom <what-Acc $>$ ate C] itta to] omoteru no?

said that] think $\mathrm{Q}$ ?

'What does John think why Mary said that Jennifer ate?'

While $(15 \mathrm{c}-\mathrm{d})$ are degraded in grammaticality for perhaps all native speakers, Pesetsky (2000: 90-91) has questioned whether the 
ungrammaticality of (15c) can be attributed to superiority, given that the two $w h$-words originate in different clauses. If that is the case then the movement of nani-o may not involve [uwh:] feature-driven movement. In the case of (15d), it is known that naze has idiosyncratic distributional properties. In particular, it "must not c-command another $w h$-phrase if they take the same scope' (Watanabe 1994: 594). In (15d) both naze and nani-o have scope in the matrix clause because whphrases in Japanese are construed with the closest question marker, and in (15d) there is only one question marker, no, in the matrix clause (Hornstein, 1995: 145). Hence the ungrammaticality may arise from naze c-commanding nani-o rather than from [ $\left.u \mathrm{wh}^{*}:\right]$ feature-driven movement.

We return to discuss what might give rise to scrambling in Section V.

\section{Acquisition of English $w h$-interrogatives by Japanese speakers: existing studies}

Given the assumptions outlined in Section II, Japanese-speaking learners of English have to acquire the following properties of English whinterrogatives:

16) a. that one $w h$-word/phrase must appear in the left periphery of an interrogative clause;

b. that such movement results from the requirement that valuing occur within the immediate projection of $[\mathrm{C}, \mathrm{Q}, u \mathrm{wh} *$ : ]

Several existing studies provide evidence that appears to suggest that Japanese speakers establish not only (16a), but also (16b). In this section, four of those studies are described. Once described, we reevaluate the strength of the evidence supporting the claim that (16b) has been established.

Yusa (1999) tested 25 intermediate-proficiency Japanese speakers of English (JSE) on a range of phenomena, and found impressively targetlike performance on a number of properties:

17) a. In a question formation task, $25 / 25$ of the participants produced target-like $w h$-fronting and subject-auxiliary inversion.

b. 20/25 were sensitive to the impossibility of contracting is to 's in cases like: Do you know where John is/*'s now? On the assumption that is-contraction is blocked when a following $w h$-phrase has been moved, this suggests that 20/25 speakers have $w h$-movement. 
c. 20/25 were sensitive to a strong crossover violation in sentences like: I know who $o_{\mathrm{i}} e_{*_{i j}}$ said has the best smile. On the assumption that the impossible binding case results from the pronoun binding a $w h$-variable, 20/25 speakers have acquired $w h$-movement.

Ohba (in progress), using a grammaticality judgement test involving scalar judgements from -2 (impossible) to +2 (possible sentence of English) found that 8 advanced proficiency JSE distinguished grammatical long-distance wh-questions (Who does the woman know that Janet loved <who>?) from ungrammatical wh-questions with weak and strong violations of subjacency like *What did Rebecca wonder who would believe <what $>$ ? (weak) and *What did your parents visit a restaurant which served $<$ what $>$ ? (strong). Mean ratings of grammaticality by the two groups are given in Table 1 .

Miyamoto and Iijima (2003) gave 65 JSE, divided into elementary and intermediate proficiency groups, a grammaticality judgement task containing 15 items involving ungrammatical how many? questions of the type:

18) a. * How many does Mary know $<$ how many $>$ girls?

b. * How many do you think $[<$ how many $>$ John likes $<$ how many $>$ girls]?

They assume that the ungrammaticality of these sentences results from a violation of the Specificity Condition (Fiengo and Higginbotham, 1981):

19) Specificity Condition: No trace must be inside a specific nominal.

If the JSE have acquired feature-driven $w h$-movement, and assuming that their grammars are constrained by the principles of UG, they should disallow sentences like (18). If they have not acquired featuredriven $w h$-movement, they may allow sentences like (18), which can be derived by scrambling, an operation that is allowed in Japanese, as we have seen.

Table 1 Mean ratings of grammaticality on a scale from -2 (impossible) to +2 (possible sentence of English)

\begin{tabular}{llll}
\hline & Grammatical & Weak & Strong \\
\hline JSE $(n=8)$ & 1.3 & -1.0 & -1.3 \\
NS $(n=15)$ & 1.7 & -1.9 & -2.0 \\
\hline
\end{tabular}


Miyamoto and Iijima found that the elementary proficiency group rejected sentences like (18) in only $50 \%$ of cases. In other words, they were responding at chance level, suggesting that they had not acquired feature-driven movement. By contrast, the intermediate proficiency group rejected these ungrammatical sentences in $78 \%$ of cases, suggesting that with longer exposure JSE can establish that in English wh-movement is feature-driven. Miyamoto \& Iijima (2003: 16) conclude that "wh-movement is scrambling in the grammar of Japanese elementary EFL learners while intermediate EFL learners allow 'real' wh-movement'.

Ojima (2005) tested both judgements of grammaticality and reaction times in making those judgements of 18 intermediate proficiency JSE, 20 more advanced JSE and 10 native controls. The sentence types concerned were grammatical declaratives involving noun complements (I like the idea that Lisa should sell the house), and ungrammatical wh-extractions from the noun complement (a weak subjacency violation), either from subject position (*Who do you like the idea that $<w h o>$ should sell the house?) or from object position (*What do you like the idea that Lisa should sell <what $>$ ?). There were five tokens of each type in the test. Results show that all 3 groups rate the grammatical declaratives as significantly more grammatical than the ungrammatical sentences, and are all significantly slower at making the decision for the ungrammatical cases than the grammatical cases, suggesting that they have established feature-driven movement.

On the face of it, the four studies just described provide considerable evidence for the claim that JSE can establish a target syntactic representation for interrogative $\mathrm{C}$, including the uninterpretable feature that forces local valuing of [ $u$ wh:] in English (Chomsky's EPP feature or Adger's *), even though this feature is absent from Japanese. That is, they have accessed an uninterpretable syntactic feature that has not been activated in primary language acquisition, contrary to the claims of Tsimpli's Interpretability Hypothesis. However, there are grounds for thinking that the evidence is not as clear-cut as it might at first seem.

Shimizu (1996), who like Ohba and Ojima also investigated the judgements of subjacency violations in English by JSE, had an interesting control in the design of his study. He not only gave an English grammaticality judgement task to 66 JSE of high intermediate 
proficiency - 1st and 2nd year university students in Tokyo - and 45 native English-speaking controls, but also gave a Japanese version of the test to 53 native speakers of Japanese. In the Japanese version, sentences were direct translations of the English sentences, with wh-words/phrases 'raised to the sentence-initial position' (Shimizu, 1996: 105). In other words, he was asking whether scrambled wh-words/phrases in decontextualized sentences in Japanese would in fact be grammatical for Japanese speakers. His test included 20 items that involved ungrammatical $w h$-movement in English, either in interrogatives or relative clauses. These were extractions from $w h$-islands and noun complements (weak violations of subjacency), and relative clauses, complex subjects and adjunct clauses (strong violations). They were balanced against 20 grammatical sentences of the same type without $w h$-extraction. Informants were asked to rate sentences on a 5-point scale from -2 (clearly impossible) to +2 (clearly possible). Mean scores are presented in Table 2.

Although Shimizu did not apply inferential statistics to the withingroup differences, it is striking that in the Japanese version of the test, the cases of scrambled $w h$-words/phrases are judged by the native Japanese speakers as less possible than the sentences without such scrambling. If it is accepted that Japanese does not have feature-driven

Table 2 Mean rating (raw scores) of three groups of speakers

\begin{tabular}{|c|c|c|c|}
\hline \multirow[t]{2}{*}{ Sentence type } & \multicolumn{2}{|c|}{ English test } & \multirow{2}{*}{$\begin{array}{l}\text { Japanese test: } \\
\text { L1 Japanese } \\
\text { ( } n=53)\end{array}$} \\
\hline & $\begin{array}{l}\text { L1 English } \\
(n=45)\end{array}$ & $\begin{array}{l}\text { JSE } \\
(n=66)\end{array}$ & \\
\hline \multicolumn{4}{|l|}{ Grammatical: } \\
\hline $\begin{array}{l}\text { wh-island } \\
\mathrm{N} \text { complement }\end{array}$ & 1.5 & 0.9 & $\begin{array}{l}1.6 \\
1.7\end{array}$ \\
\hline $\begin{array}{l}\mathrm{N} \text { complement } \\
\text { Relative clause }\end{array}$ & $\begin{array}{l}1.4 \\
1.6\end{array}$ & $\begin{array}{l}1.4 \\
1.3\end{array}$ & $\begin{array}{l}1.1 \\
1.6\end{array}$ \\
\hline Complex subject & 1.3 & 1.3 & 1.9 \\
\hline Adjunct clause & 1.8 & 1.7 & 1.9 \\
\hline \multicolumn{4}{|c|}{ Ungrammatical wh-extraction: weak violation: } \\
\hline${ }^{*} w h$-island & -0.2 & 0.1 & 0.7 \\
\hline${ }^{*} \mathrm{~N}$ complement & -0.6 & 0.1 & 0.7 \\
\hline \multicolumn{4}{|c|}{ Ungrammatical wh-extraction: weak violation } \\
\hline *Relative clause & -1.5 & -1.2 & -1.0 \\
\hline${ }^{*}$ Complex subject & -1.2 & -0.8 & 0.8 \\
\hline${ }^{*}$ Adjunct clause & -0.5 & -0.5 & 0.03 \\
\hline
\end{tabular}


wh-movement, the reason why there is this difference must have some other source. This raises the possibility that when, in the English version of the judgement task, the JSE rate the ungrammatical sentences as less possible than the grammatical, they are doing so on the same basis they would in Japanese, and not because they have acquired the [uwh:] feature of English interrogative C.

One of the arguments used by Yusa (1999) that intermediate proficiency JSE have acquired English feature-driven movement is that they are sensitive to the impossibility of contracting is to 's when it is followed by a wh-trace (Do you know where John is/*'s now?). However, it appears that contractability of $i s$ is a prosodic restriction, rather than a syntactically-determined one. As Selkirk (1996: 200) observes, English monosyllabic function words that have both a strong and weak form (can-cn, is-'s, have-'ve) generally cannot appear in their weak form in phrase-final position. The following do not involve wh-movement, but still show the restriction on contraction:

20) a. Tom's happier than Susan is (*'s)

b. Morag isn't going to the ceilidh, but Shona is (*'s)

The JSE in Yusa's study are certainly aware of this prosodic constraint in English, but this need not necessarily be evidence that they have acquired the $\left[u w^{*}:\right]$ feature of interrogative $\mathrm{C}$.

The strong crossover evidence presented by Yusa that the majority of his informants disallow binding of a wh-trace by a pronoun (I know $w h o_{\mathrm{i}} h e_{*_{i j}}$ said $t_{i}$ has the best smile) is consistent with a claim that they are not treating the constituent in embedded subject position as a null pronoun. Pronouns can be bound by other pronouns, as examples like $I$ know he ${ }_{i}$ said he $_{i}$ has the best smile illustrate. ${ }^{7}$ If the JSE had represented the $w h$-interrogative clause as: I know who he said pro ${ }_{i}$ has the best smile, they would treat who and he as coreferential. They clearly do not do this. But the fact that they do not need not necessarily result from [uwh:] driven $w h$-movement. Crucially, with the $w h$-in-situ, he and who are not coreferential: I know he said $^{\text {who } *_{i / j}}$ has the best smile. If the JSE were adopting a scrambling analysis of who in this case, they would still respond in a target-like way in their judgements.

\footnotetext{
${ }^{7}$ Strictly speaking, two pronouns can co-refer (rather than one binding the other). This distinction,
} however, is not germane to the discussion here. 
Miyamoto and Iijima (2003) argue that JSE move from a scrambling representation of English $w h$-questions to movement driven by [uwh:] on the basis of their going from allowing to disallowing split-movement questions like *How many does Mary know <how many> girls? If constructions like these are ruled out by the 'Specificity Condition' see (19) - then JSE disallow them as soon as $w h$-traces are created by movement to value [ $\left.u \mathrm{wh}^{*}:\right]$. However, it is not clear that the Specificity Condition is correct. There are a number of languages that appear to have $\left[u \mathrm{wh}^{*}:\right]$-driven movement, but which allow $w h$-word extraction out of a containing wh-phrase. Polish is one of them (example from Radford and Yokota, 2005):

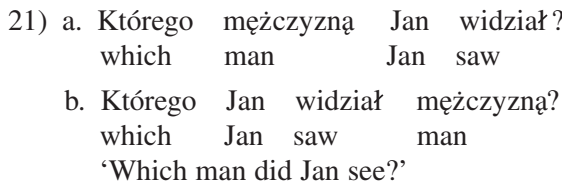

Others are Hungarian and Russian (Gavruseva and Thornton, 2001). This casts doubt on whether the constraint on extracting how many from a containing nominal in English really is to do with the presence of a $w$ h-trace. If it is not, such cases are not clear evidence that JSE have acquired [ $\left.u \mathrm{wh}^{*}:\right]$-driven $w h$-movement in English.

A reviewer suggests that whether the 'Specificity Condition' is correct or not is beside the point, given that English does not allow splitmovement questions, and the advanced L2 speakers in Miyamoto and Iijima's sample have acquired this fact. However, the point is that Miyamoto and Iijima argue that this follows precisely because Japanese speakers have acquired [ $\left.u \mathrm{wh}^{*}:\right]$ feature-driven movement in English. If there are languages that have [ $u \mathrm{wh}^{*}$ :] feature-driven movement but also allow split movement (like Hungarian, Polish and Russian), then whether a language allows split movement or not is not necessarily a consequence of [ $u \mathrm{wh} *$ :] feature-driven movement; the constraint disallowing split movement need not be connected with wh-movement per se.

The evidence that Japanese speakers of English can acquire $w h$-movement of the English type, then, may not be as clear as it at first seems. In the next section the results of an experiment involving the interpretation of multiple $w h$-questions by JSE and native speakers of English are presented. On the basis of the results, it is argued that JSE have not represented [uwh:] in their interlanguage grammars (ILGs). 


\section{IV 'Attract closest' in multiple $w h$-questions: a test case}

\section{Materials}

A test was designed to investigate the sensitivity of high proficiency Japanese speakers of English (JSE) to the 'Attract Closest' principle in biclausal interrogative sentences. This should apply if the interlanguage grammars of the JSE are broadly UG-derived, and if they have acquired the uninterpretable feature of English that drives movement of a whword/phrase to interrogative C (i.e. [uwh*:]), leading them to reject what are traditionally called 'superiority' and 'subjacency' violations. A superiority violation is illustrated in (22b), and a subjacency violation in $(22 c)$.

22) a. When did Sophie's brother warn [Sophie would phone who $<$ when $>$ ]?

b. * Who did Sophie's brother warn [Sophie would phone $<$ who $>$ when]?

c. * When did Sophie's brother warn [who Sophie would phone $<$ who $>$ $<$ when $>$ ]?

There were two reasons for choosing biclausal sentences rather than single clause sentences. First, to avoid the possibility that JSE reject violations like *What did who buy? because they have a conscious strategy excluding $d o$-support with subject $w h$-words (apparently taught as such in some English classrooms in Japan). Second, to allow for two possible scope readings of the matrix $w h$-word: one in the matrix clause and the other in the embedded clause, as illustrated in (23):

23) a. When did Sophie's brother warn $<$ when $_{1}>$ [Sophie would phone who $<$ when $_{2}>$ ]?

b. Who did Sophie's brother warn $<$ who $_{1}>$ [Sophie would phone $<* w^{*} o_{2}>$ when]?

This allowed us to exploit a tension between the pragmatic plausibility of an embedded scope reading and its syntactic impossibility because of a superiority or subjacency violation. We used this tension in the construction of a version of a truth value judgement task (Crain \& Thornton, 1998), which took the form: story + question +3 possible answers. All answers in the experimental items were pragmatically 'true' given the story, but possible violations of 'Attract Closest' restricted whether they were grammatically possible answers or not. To illustrate:

Example test item:

Sophie was angry. Her holiday had been ruined because the hotel she had booked through a travel agency was full, and she had to sleep in a tent. Sophie's brother was a 
friend of Norman who owned the travel agency. He spoke to Norman on Thursday and told him that Sophie would be phoning his manager, Mrs Smith, the following day to ask for her money back.

Question: Who did Sophie's brother warn Sophie would phone when?

Answer 1: He warned Norman that Sophie would phone on Friday.

Answer 2: He warned that Sophie would phone Mrs Smith on Friday.

Answer 3: He warned Norman on Thursday that Sophie would phone.

Answer 1 corresponds to who having scope in the matrix clause (He warned who?), and when in the embedded clause (Sophie would phone when?), and is both pragmatically plausible, given the story, and grammatically possible. Answer 2 corresponds to both who and when having scope in the embedded clause (Sophie would phone who when?). This is pragmatically plausible given the story, but violates superiority (when being superior to object who). Answer 3 corresponds to when having scope in the matrix clause (syntactically impossible), but again the sentence is pragmatically plausible, given the story. The test took the following form:

- The wh-words used in the questions were: who, what, where, when. There were no $w h$-phrases like which person, what time, etc., since these are not subject to superiority (Which book did which student buy?)

- All embedded clauses in the questions were finite.

- Eight test items served as a 'syntax test'. These involved questions with a single $w h$-word in the matrix clause of a biclausal structure. In 4 of these, the scope of the $w h$-word was unambiguously the embedded clause, as shown in (24a). In the other 4 , scope was ambiguously the matrix or embedded clause, as shown in (24b).

24) a. Who did Tom discover [Mary had met $<$ who $>$ ]?

b. Who did the specialist promise $<$ who $_{1}>$ [Mary would see $<$ who $_{2}>$ ]?

A context in which (24b) is plausible might be where Mary has an eye problem (e.g. cataracts). On this scenario, a response to the scope of who in the matrix clause could be: 'The specialist promised her husband that she would see (again)', and a response to the scope of who in the embedded clause could be: 'The specialist promised that Mary would see her husband (again)'.

The purpose of the syntax test was to ensure that informants selected for analysis on the experimental items could appropriately interpret 
long-distance wh-moved structures. Informants were selected for analysis on the experimental items if they chose appropriate answers and rejected inappropriate answers on at least 6 out of 8 items of the syntax test.

There were 14 main experimental items involving multiple whquestions, distributed as follows:

- The matrix $w h$-word was interpretable only in the embedded clause, with no violation of superiority/subjacency, as shown in (25a).

- The matrix $w h$-word was interpretable either in the main or the embedded clause, with no violation of superiority/subjacency, as shown in (25b).

- The matrix wh-phrase was pragmatically plausible either in the main clause or the embedded clause, but the embedded clause interpretation was blocked by a superiority violation, as shown in $(25 c)$.

- The matrix $w h$-phrase was pragmatically plausible either in the main or embedded clause, but the embedded clause interpretation was blocked by an intervening wh-word in the embedded clause ('subjacency'), but without a superiority violation, as shown in (25d).

- The matrix $w h$-phrase was pragmatically plausible either in the main clause or the embedded clause, but the embedded clause interpretation was blocked by a superiority violation and a subjacency violation, as shown in (25e). The 8 'syntax test' items and 14 experimental items were randomized with 16 other items to produce a 38 -item instrument.

25) a. Who did the headteacher suspect $[<$ who $>$ had taken what $]$ ? (3 tokens)

b. When did Henry remember $<$ when $_{1}>$ [Louise had lost what $<$ when $_{2}>$ ]? (4 tokens)

c. Who did Sophie's brother warn $<$ who $_{1}>\left[\right.$ Sophie would telephone $<* w^{*} o_{2}>$ when]? (3 tokens)

d. When did Rupert discover $<$ when $_{1}>$ [who Nora had met $<$ who $>$ $<{ }^{*}$ when $_{2}>$ ]? (3 tokens)

e. Who did the weather office warn $<$ who $_{1}>$ [when the hurricane might strike $<*$ who $_{2}><$ when $>$ ] $\left(1\right.$ token $\left.^{8}\right)$

\footnotetext{
${ }^{8}$ There were more intended tokens of this type in the test instrument, but due to an error in design
} that emerged only after administration of the test, just 1 token was countable. 


\section{Participants}

An initial cohort of 39 Japanese speakers of English (JSE) and a control group of 19 native speakers of English (NSE) took the test. Those whose performance was analysed to test the research questions were then selected as follows:

- Any JSE who had lived in an English-speaking country before puberty was excluded (to ensure that participants were most likely to have been beyond a putative critical period when first significant acquisition occurred): 2 participants were excluded for this reason.

- Any speaker (JSE or NSE) who failed the syntax test was excluded. Sixteen JSE and 7 NSE failed the syntax test. This does not, however, mean that the test was unreliable. The items in the syntax test were present to ensure that the participants whose responses to constraints on long-distance movement were analysed allowed long-distance construal when no such constraints were present. Four of the items in the syntax test allowed both long-distance and matrix construal. The participants who failed to choose appropriate answers in at least 6 out of the 8 cases were showing a preference for the matrix construal option in these cases. By eliminating speakers with such a preference, the aim was to reduce a potentially confounding variable in the analysis.

- Any speaker (JSE or NSE) who chose all 3 answers in more than 5 of the 29 items where only 2 answers were grammatically possible was excluded (to eliminate those with a tendency to respond 'yes' to test items). Two JSE and 1 NSE were excluded on this basis. ${ }^{9}$

This left 19 experimental JSE (12 women, 7 men; age range: 22-43 years, length of residence in an English-speaking country: 9 months-18 years), and a control group of 11 NSE.

\footnotetext{
${ }^{9} \mathrm{As}$ in the case of the syntax test, elimination of subjects on this criterion was an attempt to reduce another potentially confounding variable: test bias, i.e. a tendency to accept all three answers in an item. A reviewer wonders whether the criterion should not have been to exclude anyone who chose all three answers in 15/29 items (50\%), rather than more than 5/29 items (17\%). Our criterion, however, gives the JSE a much better chance to show that they really know the locality constraints operating in English, because only those speakers were chosen who were making positive decisions about which answers were correct. Had we included JSE who allowed all 3 answers in 50\% of cases (i.e. allowing violations of superiority and subjacency) the odds would have been strongly in favour of confirming our null hypothesis that older JSE do not establish [uw*:] feature-driven movement.
} 


\section{Procedure}

The task was presented to participants as a paper - and - pencil test. Each item (that is, story + question +3 answers) was on a separate sheet (with no possible return to earlier answers). Participants were asked to choose all the appropriate answers to the question. For the JSE, the story component was in Japanese (following a design used by Dekydtspotter et al., 1997; 2001) to reduce responses that might be due to a misunderstanding of the story. The question and the answers, however, were in English. The test was untimed.

Each answer chosen by an informant was given a score of 1 and each unchosen answer a score of 0 . Group means were then calculated for responses to each of the three answers. The non-parametric Mann-Whitney $U$ test was used to test for significant differences between and within the two groups of informants. The alpha level was set at $p<.05 .^{10}$

\section{Group results}

The mean choices of answer by each group corresponding to the first $w h$-word in the sentence having scope in the matrix or embedded clause are presented in Table 3. (The number of choices of the third response, which typically corresponded to the embedded wh-word having scope in the matrix clause - always ungrammatical in English - were almost never chosen, so results for this are not reported.) Arrows linking scores in the table indicate significant differences, as determined by the Mann-Whitney U test.

Question types (a) and (b) in Table 3 report the frequency with which participants chose answers where the matrix $w h$-word in the question has scope in the embedded clause and there is no superiority/ subjacency violation. For the (a) answers there was no matrix scope possibility; for the (b) answers scope was either in the matrix or the embedded clause. JSE and NSE responded very similarly in these cases, with no significant difference between them. (For (a) $p=0.9$; for

\footnotetext{
${ }^{10} \mathrm{~A}$ non-parametric test (rather than a parametric test like ANOVA) was chosen because the native group were categorical in their responses to two of the test conditions. This meant that their results on these items were not normally distributed. (In fact a one-way ANOVA was run just for the purposes of comparison with the Mann-Whitney U test. It produced similar values.)
} 
Table 3 Multiple wh-questions: mean choice of answers corresponding to the scope of a matrix wh-word (significant differences indicated by arrows)

\begin{tabular}{|c|c|c|c|c|c|c|c|}
\hline & \multicolumn{3}{|c|}{ Embedded scope } & & & \multicolumn{2}{|c|}{ Matrix scope } \\
\hline & JSE & & NSE & & & JSE & NSE \\
\hline $\begin{array}{l}\text { Question type (a): } \\
k=3 \\
\text { SD }\end{array}$ & $\begin{array}{l}0.96 \\
0.11\end{array}$ & & $\begin{array}{l}0.97 \\
0.10\end{array}$ & & & $\begin{array}{l}- \\
-\end{array}$ & $\begin{array}{l}- \\
-\end{array}$ \\
\hline $\begin{array}{l}\text { Question type (b): } \\
k=4 \\
\text { SD }\end{array}$ & $\begin{array}{l}0.78 \\
0.26\end{array}$ & & $\begin{array}{l}0.75 \\
0.19\end{array}$ & $\uparrow \uparrow \uparrow$ & & $\begin{array}{l}0.92 \\
0.12\end{array}$ & $\begin{array}{l}0.91 \\
0.17\end{array}$ \\
\hline $\begin{array}{l}\text { Question type (c): } \\
k=3 \\
\text { SD }\end{array}$ & $\begin{array}{l}0.75 \\
0.29\end{array}$ & $\longleftrightarrow$ & $\begin{array}{l}0.33 \\
0.30\end{array}$ & 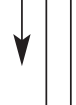 & $\uparrow$ & $\begin{array}{l}0.88 \\
0.17\end{array}$ & $\begin{array}{l}0.85 \\
0.27\end{array}$ \\
\hline $\begin{array}{l}\text { Question type }(d) \text { : } \\
k=3 \\
\text { SD }\end{array}$ & $\begin{array}{l}0.58 \\
0.37\end{array}$ & $\longleftrightarrow$ & $\begin{array}{l}0.21 \\
0.31\end{array}$ & $\checkmark$ & $\uparrow$ & $\begin{array}{l}0.93 \\
0.14\end{array}$ & $\begin{array}{l}1.00 \\
0.00\end{array}$ \\
\hline $\begin{array}{l}\text { Question type (e): } \\
k=1 \\
\text { SD }\end{array}$ & $\begin{array}{l}0.58 \\
0.51\end{array}$ & $\longleftrightarrow$ & $\begin{array}{l}0.00 \\
0.00\end{array}$ & & $\forall \forall$ & $\begin{array}{l}0.95 \\
0.23\end{array}$ & $\begin{array}{l}0.91 \\
0.30\end{array}$ \\
\hline
\end{tabular}

Notes: Question type (a) = embedded scope only, no syntactic violation, e.g. Who did the head-teacher suspect [<who $>$ had seen what]?; Question type (b) = matrix and embedded scope, no syntactic violation,e.g. When did Henry remember $\left\langle\right.$ when $\left.{ }_{1}\right\rangle$ [Louise had lost what $<$ when $_{2}>$ ]?; Question type (c) = matrix and *embedded scope, violation of superiority, e.g. Who did Sophie's brother warn $\left\langle\right.$ who ${ }_{1}>$ [Sophie would phone $<{ }^{*}$ who $_{2}>$ when]?; Question type (d) = matrix and *embedded scope, violation of subjacency, e.g. When did Rupert discover $<$ when ${ }_{1}>$ [who Nora had met $<$ who $><{ }^{*}$ when $_{2}>$ ]?; Question type (e) = matrix and *embedded scope, violation of superiority and subjacency, e.g. Who did the weather office warn $\left\langle\right.$ who $\left.{ }_{1}\right\rangle$ [when the hurricane might strike $<{ }^{*}$ who $_{2}><$ when $>$ ]?

embedded scope in (b) $p=0.55$; and for matrix scope $p=0.94$.) This is an important baseline. It shows that the experimental participant are able to interpret long-distance wh-word ... gap dependencies and recognize scope ambiguities in the same way as native speakers.

Question type (c) reports answers where the matrix wh-word in the question can be interpreted either in the matrix or embedded clause in terms of pragmatic plausibility, but where a superiority violation should block the embedded reading. Such a reading is blocked for the NSE who are significantly different in their responses here to embedded scope than in the (b) case $(p=0.001)$. The JSE, however, are not significantly different in their responses to (b) and (c) $(p=0.73)$. Furthermore, there is a significant between-groups effect for the embedded scope reading in (c) $(p=0.002)$, but not for the matrix scope reading $(p=0.88)$. The JSE are not apparently sensitive to superiority effects. 
Question type (d) reports answers where again the matrix wh-word in the question can be interpreted both in the matrix and embedded clause in terms of pragmatic plausibility, but where a subjacency violation should block the embedded reading. This is the case for the NSE. They are significantly different in their responses to embedded scope compared with their answers in the (b)-type cases $(p=0.001)$. Furthermore, their responses to subjacency violations are not significantly different from their responses to superiority violations ( $p=0.14)$. The frequency of choices of embedded scope by the JSE is lower in this case than in cases (b) and (c), but this difference does not reach significance ((d) compared with (b): $p=0.08$; (d) compared with (c): $p=0.26)$. They are again significantly different from the NSE $(p=0.01)$. Statistically, then, the JSE are not sensitive to subjacency violations. There is, nevertheless, a tendency to reject embedded readings when a subjacency-like violation occurs. ${ }^{11}$

Finally, in the one case where an embedded scope reading for a matrix $w h$-word violates both superiority and subjacency, this has a strengthening effect on the judgements of the NSE. None of them accept the embedded reading, and this response is significantly different from the cases involving superiority or subjacency violations alone ((e) compared with (c): $p=0.002$; (e) compared with (d): $p=0.01$ ). Again the JSE are not significantly different in their responses to this case from the earlier cases ((e) compared with (c): $p=0.59$; (e) compared with $(\mathrm{d}): p=0.82)$. But they are significantly different from the NSE $(p=0.002)$.

The results suggest that despite the awareness of the JSE in this study of the interpretive possibilities of long distance wh-word ... gap dependencies, and despite reports from earlier studies that Japanese speakers of English can acquire a range of properties associated with English wh-movement to interrogative $\mathrm{C}$, they are nevertheless not sensitive to constraints that apply to movement: superiority and

\footnotetext{
${ }^{11}$ The reader may wonder why the NSE accept answers that violate superiority (33\% acceptance) and subjacency (21\% acceptance) at all. In complex interpretation tasks of the kind used in this study, performance or pragmatic factors may lead native speakers to accept constructions that violate principles of UG. The important point is whether natives make a significant distinction between grammatical cases and ungrammatical cases, as they do in this study. For discussion of this point see White, 2003b: 29-30.
} 
subjacency. By implication, they have some other representation for wh-word ... gap dependencies in English than movement to C[Q] driven by a [uwh:] feature. Their ILGs are missing a feature, despite appearances.

\section{Item and individual participant analysis}

It is well-known that group mean scores may conceal different patterns of response both to tokens within a given type, and between individuals. To test whether there were any orthogonal patterns of response to the group findings for the Japanese speakers, we examined within-group responses to the tokens making up each type, and examined individual response patterns different from the group pattern. There were no significant differences in responses to tokens within each type ((a) to (d) of Table 3: recall that there was only one token representing type (e), so this analysis could not be applied here).

In looking at the performance of individual participants there was just one who appeared to fall within the range of the native control group by not selecting interpretations that would violate either superiority or subjacency. However, closer examination suggests that this might be the effect of a response bias, rather than acquisition of $\left[\mathrm{C}, \mathrm{Q}, u \mathrm{wh}^{*}:\right]$. The responses are presented in Table 4.

Although this speaker appears to be rejecting answers involving embedded scope when a superiority/subjacency violation would result, the shaded responses to the (b)-type questions make it clear that he or she is also rejecting 3 out of 4 embedded scope readings where no syntactic violation is involved. This suggests that whenever a matrix scope interpretation is available, this speaker typically prefers that reading: a response bias. Other individuals do not differ significantly from the group mean performance. ${ }^{12}$

\footnotetext{
${ }^{12} \mathrm{~A}$ reviewer asks whether this individual's performance may not also be considered evidence that $\mathrm{s} / \mathrm{he}$ has acquired [ $u \mathrm{wh} *$ :] feature-driven movement. It can, of course, be interpreted in this way and this would be a counter-example to our claim that post-critical-period Japanese-speaking learners of English do not have access to [uwh:]. Our point in the text is that the results for this speaker shown in Table 4 are also consistent with a response bias. Hence, whether this speaker has [uwh*:] in her/his grammar is undecidable.
} 
Table 4 Mean choice of answers per token compared with expected native choice made by one Japanese participant $(1=$ selected, $0=$ unselected $)$

\begin{tabular}{|c|c|c|c|c|}
\hline \multirow[t]{2}{*}{ Token } & \multicolumn{2}{|c|}{ Embedded interpretation } & \multicolumn{2}{|c|}{ Matrix interpretation } \\
\hline & $\begin{array}{l}\text { Japanese } \\
\text { participant } \\
\text { choice }\end{array}$ & $\begin{array}{l}\text { Expected } \\
\text { response }\end{array}$ & $\begin{array}{l}\text { Japanese } \\
\text { participant } \\
\text { choice }\end{array}$ & $\begin{array}{l}\text { Expected } \\
\text { response }\end{array}$ \\
\hline \multicolumn{5}{|c|}{ Question type (a) } \\
\hline 1 & 1 & 1 & - & - \\
\hline 2 & 1 & 1 & - & - \\
\hline 3 & 1 & 1 & - & - \\
\hline \multicolumn{5}{|c|}{ Question type (b) } \\
\hline 1 & 0 & 1 & 1 & 1 \\
\hline 2 & 0 & 1 & 1 & 1 \\
\hline 3 & 0 & 1 & 1 & 1 \\
\hline 4 & 1 & 1 & 1 & 1 \\
\hline \multicolumn{5}{|c|}{ Question type (c) } \\
\hline$* 1$ & 0 & 0 & 1 & 1 \\
\hline$* 2$ & 0 & 0 & 1 & 1 \\
\hline *3 & 0 & 0 & 1 & 1 \\
\hline \multicolumn{5}{|c|}{ Question type (d) } \\
\hline$* 1$ & 0 & 0 & 1 & 1 \\
\hline$* 2$ & 0 & 0 & 1 & 1 \\
\hline *3 & 0 & 0 & 1 & 1 \\
\hline \multicolumn{5}{|c|}{ Question type (e) } \\
\hline$* 1$ & 0 & 0 & 1 & 1 \\
\hline
\end{tabular}

Note: * indicates ungrammaticality

\section{Discussion}

The investigation of the way that highly proficient Japanese speakers of English interpret bi-clausal multiple $w h$-questions has shown that while they allow both embedded and matrix readings for a main clause $w h$ word, where such readings are possible, they also allow embedded readings that violate the Attract Closest Principle. Their responses are not significantly different on these two types, although they are less likely to accept what are traditionally called 'subjacency' violations than 'superiority' violations. In contrast, native speaker controls show significant differences in their acceptance of the grammatical and the ungrammatical readings. The Japanese speakers are significantly different from the natives in this respect. This is not an effect of a tendency to respond 'yes' to all answers, because each test item included a third pragmatically plausible, but grammatically impossible, response that typically corresponded to the embedded $w h$-word having scope in the 
matrix clause. This is always impossible in English, but is in fact possible in Japanese in cases like (26):

26) John-wa $\left[_{\mathrm{CP}}\right.$ Mary-ga kinou nani-o kat-ta ka] oboete imasu ka? John-topic [Mary-Nom yesterday what-Acc buy-past Q] remember is Q? 'What did John remember whether Mary bought yesterday?'13

This type of answer was almost never chosen.

We interpret the results as consistent with the claim that the speakers investigated, although high proficiency speakers of English, some with long immersion, have failed to represent [uwh:] in interrogative $\mathrm{C}$, which gives rise to the effects of the Attract Closest Principle. Two questions arise from this interpretation. First, why exactly is this feature missing? Second, why are JSE nevertheless so successful in producing and interpreting English wh-interrogatives in many other respects, as illustrated by the studies reported in Section III?

As argued above, the Interpretability Hypothesis of Tsimpli (2003) proposes that uninterpretable syntactic features not selected during primary language acquisition from the inventory of features given by the initial state of UG will disappear following a critical period. Speculatively, this may be the effect of functional economy in the organization of the language faculty or energy efficiency constraints imposed by the neuro-anatomy of brain tissue (two possibilities considered in Section I). The results obtained in the present study are consistent with this hypothesis. The performance of the JSE in interpreting multiple $w h$-questions appropriately, but failing to be constrained by the Attract Closest Principle, would follow if their grammars are UGconstrained, but lack the [uwh:] feature, which is absent in Japanese. This implies that the nature of ultimate attainment in a second language is partly, but not wholly, L1-determined. The prediction is that speakers of an L1 (or L1s) with uninterpretable feature $[u \gamma]$ also present in the L2 will fully acquire target representations involving the feature $[u \gamma]$. But speakers of an L1 (or L1s) lacking $[u \gamma]$ who are exposed to an L2 beyond some point of early development will no longer have that feature available, and will construct representations for the relevant L2 structures with alternative resources made available by UG. Note that

\footnotetext{
${ }^{13}$ The Japanese sentence can be interpreted both as 'What did John remember whether Mary bought yesterday?' and 'Did John remember what Mary bought yesterday?' This is an effect of nani 'what' being in situ; it can be interpreted either as within the scope of matrix $k a$, or embedded $k a$.
} 
the claim is that L2 grammars are still UG-constrained, but with a potentially reduced feature set.

This position requires, then, some explanation of how JSE can be so successful in many respects in their representation of English $w h$-interrogatives. The suggestion that we make has been raised as a possibility by Miyamoto and Iijima (2003) and Ojima (2005) (although Miyamoto and Iijima regard it only as a temporary feature of development, and Ojima raises the possibility in order to argue against it). It is that JSE represent fronted $w h$-words/phrases as cases of obligatory $w h$-scrambling, and that this is a persistent property of their ILGs for English.

A number of the world's languages appear to require leftward movement of $w h$-phrases for reasons other than local valuing of [uwh:]. Bošković (2002) (following Stjepanović, 1999) argues that the driving force for the movement of the second wh-phrase in multiple whfronting languages like Bulgarian, Serbo-Croatian and Russian, as illustrated in (27), is Focus and not a [wh] feature on C[Q]:

$\begin{array}{ll}\text { 27) a. Koj kogo običa } & \text { Bulgarian } \\ \text { Who whom loves } & \\ \text { 'Who loves whom?' } & \\ \text { b. Ko koga voli? } & \text { Serbo-Croatian } \\ \text { Who whom loves } & \text { Russian } \\ \text { c. Kto kogo ljubit? } & \end{array}$

Kobayashi (2000) and Bailyn (2001) suggest that scrambling in Japanese is leftward movement to a Focus position. Kawamura (2004) suggests that scrambling involves movement to satisfy a $\Sigma$-feature, and that such movement has different properties from $w h$-movement.

Suppose that the JSE in the present study have established ILGs for English where a wh-phrase moves leftwards obligatorily to satisfy a Focus requirement rather than the $\left[u \mathrm{wh}^{*}:\right]$ feature of C. ${ }^{14}$ How might

\footnotetext{
${ }^{14} \mathrm{~A}$ reviewer asks why the JSE have assumed that $w h$-scrambling in English is obligatory when in Japanese scrambling is optional. We assume that English input plays a role here. In Japanese, when scrambling to Focus occurs a [uFoc*:] feature is involved, given the logic of our account. However, $[u$ Foc*:] can target any focused constituent in a sentence in Japanese, not just $w h$-words/phrases, such that $w h$-words/phrases are not always scrambled. English input will provide evidence for a Japanese learner that a $w h$-word/phrase is always focused. Hence the obligatory scrambling of $w h$-words/phrases in the ILGs of Japanese speakers results from the availability of the feature $\left[u \mathrm{Foc}^{*}:\right]$ in conjunction with a distributional pattern observed in input.
} 
this account for the observed behaviour? Assume that the JSE have established a Focus projection in the left periphery of C[Q] sentences with an interpretable feature relating to the identification of nonpresupposed information in the clause - call it [ident] for convenience and an uninterpretable feature $\left[u \mathrm{Foc}^{*}:\right]$. Further assume that an interpretable [Foc] feature is assigned to all $w h$-words, on the grounds that $w h$-words inherently identify non-presupposed information (Kobayashi, 2000; É. Kiss, 2002). In multiple wh-questions, one of the $w h$-words must move to value [uFoc*:]. However, this movement relates to focus interpretation not to interrogative interpretation. The semantic component interprets the dependency between $[\mathrm{C}, \mathrm{Q}, u \mathrm{wh}]$ and an in-situ $w h$-word/phrase just as in Japanese. In other words, while focus interpretation might involve the head of a $w h$-chain, interrogative interpretation involves the foot of the chain, the copy of the $w h$-word/phrase, as illustrated in (28):

Focus interpretation

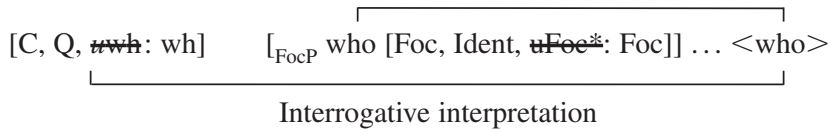

Since the interrogative interpretation is determined over in-situ whwords/phrases, violations of the Attract Closest Principle do not arise.

However, it might seem that now Focus movement would be subject to Attract Closest. Our speculation about this is that for the purposes of focus interpretation, all potentially focus-able constituents within the same clause are equidistant from the Foc constituent and, hence, that clause-internally any constituent with a [Foc] feature is a potential target of movement to FocP without violation of Attract Closest. This could be because focus interpretation is qualitatively different from interrogative interpretation, and does not need to 'see' hierarchical structure in searching for a target to value [uFoc*:]. While this is an extremely tentative suggestion, observe that some account of why one wh-word can cross another for focus interpretation is required to explain why scrambling in Japanese does not violate the Attract Closest Principle. The account of interrogative interpretation involving the foot of a wh-chain and focus interpretation involving the head of the chain is in essence that proposed by Kobayashi for scrambled $w h$-words in Japanese. 
Where a $w h$-word crosses another already moved to a FocP, as in:

29) When did Rupert discover $\left[\left[_{\text {FocP }}\right.\right.$ who] Nora had met $<$ who $><$ when $\left.>\right]$ ?

it was found that the JSE in this study were less likely to accept the embedded interpretation, although this tendency was not significant. This could be explained as an effect of Attract Closest. Although constituents with a [Foc] feature might be equidistant from FocP within the same clause, this may not apply to a FocP in a higher clause:

30) $\left[{ }_{\mathrm{CP}}\left[\left[_{\mathrm{FocP}}\right.\right.\right.$ when $] \ldots \quad\left[\left[_{\mathrm{CP}}\left[\left[_{\mathrm{FocP}}\right.\right.\right.\right.$ who $] \quad \ldots \quad<$ who $><$ when $\left.\left.>\right]\right]$

1

This assumption could also explain the performance of JSE in judging subjacency violations in the studies of Shimizu (1996), Ojima (2005) and Ohba (in progress).

Finally, the results of the present study suggest that caution is required in interpreting apparent target-like L2 performance as evidence for the acquisition of underlying properties of grammar assumed to be present in the grammars of native speakers. If, in a given domain, the only difference between a native grammar and the ILG of a late second language learner is an uninterpretable feature, but all other resources of UG are still available, then the performance of that learner could look very like that of a native. Subtle testing of a range of properties in the relevant domain might be required before one can say with confidence that feature $[u \gamma]$ is present in the grammar.

\section{Acknowledgements}

We would like to thank Andrew Radford, the audiences at Eurosla 2002 (Basel University) and GASLA 72004 (Indiana University) and two anonymous Second Language Research reviewers for helpful comments on earlier versions of this article. We alone are responsible for remaining weaknesses.

\section{References}

Adger, D. 2003: Core syntax: a minimalist approach. Oxford University Press. Aoun, J. and Li, Y.-H.A. 2003: Essays on the representational and derivational nature of grammar: the diversity of wh-constructions. MIT Press. 
Bailyn, J.F. 2001: On scrambling: a reply to Bošković and Takahashi. Linguistic Inquiry 32, 635-57.

Bateson, P. and Martin, P. 1999: Design for a life: how behaviour develops. Random House.

Bošković, Z. 2002: On multiple wh-fronting. Linguistic Inquiry 33, 351-83.

Brown, C. 2000: The interrelation between speech perception and phonological acquisition from infant to adult. In Archibald, J., editor, Second language acquisition and linguistic theory. Blackwell.

Chomsky, N. 1995: The Minimalist Program. MIT Press.

— 1998: Minimalist inquiries: the framework. MIT Working Papers in Linguistics 15, 1-56. Also published in Martin, R., Michaels, D. and Uriangereka, J., editors, 2000: Step by step: essays on minimalist syntax in honor of Howard Lasnik. MIT Press.

— 2001: Derivation by phase. In Kenstowicz, M., editor, Ken Hale: a life in language. MIT Press.

Crain, S. and Thornton, R. 1998: Investigations in Universal Grammar: a guide to experiments on the acquisition of syntax. Cambridge University Press.

Dekydtspotter, L. and Sprouse, R. 2001: Mental design and (second) language epistemology: adjectival restrictions of $w h$-quantifiers and tense in English-French interlanguage. Second Language Research 17, 1-35.

Dekydtspotter, L., Sprouse, R. and Anderson, B. 1997: The interpretive interface in L2 acquisition: the process-result distinction in English-French interlanguage grammars. Language Acquisition 6, 297-332.

É. Kiss, K. 2002: The syntax of Hungarian. Cambridge University Press.

Eubank, L. and Gregg, K. 1999: Critical periods and (second) language acquisition: divide et impera. In Birdsong, D., editor, Second language acquisition and the critical period hypothesis. Lawrence Erlbaum.

Fiengo, R. and Higginbotham, J. 1981: Opacity in NP. Linguistic Analysis 7: 395-422.

Gavruseva, E. and Thornton, R. 2001: Getting it right: acquisition of whosequestions in child English. Language Acquisition 9, 229-67.

Goad, H., White, L. and Steele, J. 2003: Missing Inflection in L2 acquisition: defective syntax or L1-constrained prosodic representations? Canadian Journal of Linguistics 48, 243-63.

Hornstein, N. 1995: Logical Form: from GB to minimalism. Blackwell.

Kawamura, T. 2004: A feature-checking analysis of Japanese scrambling. Journal of Linguistics 40, 45-68.

Kobayashi, A. 2000: The third position for a wh-phrase. Linguistic Analysis 30, 177-215.

Lardiere, D. 1998a: Case and tense in the 'fossilized' steady state. Second Language Research 14, 1-26. 
1998b: Dissociating syntax from morphology in a divergent end-state grammar. Second Language Research 14, 359-75.

2000: Mapping features and forms in second language acquisition. In Archibald, J., editor, Second language acquisition and linguistic theory. Blackwell.

Larson Hall, J. 2004: Predicting perceptual success with segments: a test of Japanese speakers of Russian. Second Language Research 20, 32-76.

Long, M. 2003: Stabilization and fossilization in interlanguage development. In Doughty, C. and Long, M., editors, The handbook of second language acquisition. Blackwell.

Miyagawa, S. 2003: A-movement scrambling and options without optionality. In Karimi, S., editor, Word order and scrambling. Blackwell.

Miyamoto, Y. and Iijima, Y. 2003: On the existence of scrambling in the grammar of Japanese elementary EFL learners. In Foster-Cohen, S. and Pekarek Doehler, S., editors, Eurosla Yearbook 3, 7-27.

Myles, F. 2004: From data to theory: the over-representation of linguistic knowledge in SLA. Transactions of the Philological Society 102, 139-68.

Ohba, H. in progress: The acquisition of $w h$-movement in English questions and relative clauses by native speakers of Japanese. Doctoral dissertation in progress, University of Essex.

Ojima, S. 2005: Theory and evidence in second language research: the acquisition of English by native speakers of Japanese. Unpublished doctoral dissertation. University of Essex.

Pesetsky, D. 2000: Phrasal movement and its kin. MIT Press.

Pesetsky, D. and Torrego, E. 2001: T-to-C movement: causes and consequences. In Kenstowicz, M., editor, Ken Hale: a life in language. MIT Press.

Prévost, P. and White, L. 2000: Missing surface inflection or impairment in second language acquisition? Evidence from tense and agreement. Second Language Research 16, 103-33.

Radford, A. 2004: Minimalist syntax: exploring the structure of English. Cambridge University Press.

Radford, A. and Yokota, H. 2005: Principles, parameters and transfer in second language acquisition: evidence from long-distance $w h$-questions produced by elementary Japanese learners of English. Unpublished manuscript, University of Essex.

Saito, M. 1992: Long distance scrambling in Japanese. Journal of East Asian Linguistics 1, 69-118.

Saito, M. and Fukui, N. 1998: Order in phrase structure and movement. Linguistic Inquiry 29, 439-74.

Selkirk, E. 1996: The prosodic structure of function words. In Morgan, J. and Demuth, K., editors, Signal to syntax: bootstrapping from speech to grammar in early acquisition. Lawrence Erlbaum. 
Shimizu, T. 1996: A study of Japanese learners' acquisition of English subjacency in wh-movement and topicalization. JACET, 99-116.

Stjepanović, S. 1999: What do second position cliticization, scrambling, and multiple wh-fronting have in common? Unpublished doctoral dissertation, University of Connecticut, Storrs.

Takahashi, D. 1993: Movement of wh-phrases in Japanese. Natural Language and Linguistic Theory 11, 655-78.

Tanaka, H. 1999: LF wh-islands and the minimal scope principle. Natural Language and Linguistic Theory 17, 371-402.

Tsimpli, I.-M. 2003: Features in language development. Paper presented at the Eurosla conference, University of Edinburgh.

Tsimpli, I.-M. and Dimitrakopoulou, M. to appear: The interpretability hypothesis: evidence from wh-interrogatives in L2 acquisition. Second Language Research.

Watanabe, S. 1994: (Anti-)superiority as weak crossover. MIT Working Papers in Linguistics 24, 393-411.

White, L. 2003a: Fossilization in steady state L2 grammars: persistent problems with inflectional morphology. Bilingualism: Language and Cognition 6, 129-41.

2003b: Second language acquisition and Universal Grammar. Cambridge University Press.

Yusa, N. 1999: Multiple-specifiers and wh-island effects in L2 acquisition. In Klein, E. and Martohardjono, G., editors, The development of second language grammars: a generative approach. John Benjamins. 